\title{
Şanlıurfa Taşının Bazı Mühendislik Özellikleri ve İktisadi Yönden İncelenmesi
}

\author{
${ }^{1}$ Celal AĞAN, ${ }^{2}$ Mustafa ŞíT \\ ${ }^{1}$ Harran Üniversitesi, İnşaat Mühendisliği Bölümü, Şanlıurfa,Türkiye, celalagan@ harran.edu.tr, \\ 2Harran Üniversitesi,Seyahat İşletmeciliği Bölümü, Şanlıurfa,Türkiye,msit@ harran.edu.tr, \\ Araştırma Makalesi \\ Geliş Tarihi: 22.11.2017 \\ Kabul Tarihi: 27.07.2018
}

\section{$\ddot{\mathbf{O z}}$}

Şanlıurfa taşı güzel görünümü, kolay kesilebilmesi, 1S1 yalıtımı ve dayanıklılığı sayesinde Şanlıurfa'da antik çağlardan beri yaşayan tüm medeniyetlerin en önemli barınak malzemesi olmuştur. Ancak, betonun icadından sonra Şanlıurfa taşı önemini yitirmiş ve çoğunlukla çimento sanayiinde agrega ve mıcır üretiminde kullanılmıştır. Bu çalışmada, Şanlıurfa taşının mühendislik özellikleri ve cilalanabilirliği incelenmiş, agrega ve mıcır olarak kullanılmasının neden olduğu gelir kayıpları sorgulanarak ekonomik analiz yapılmıştır. Çalışmada literatürde ki çalışmalardan farklı olarak ekonomik analiz eklenmiştir. Sonuçta, Şanlıurfa taşının uluslararası standartların gereksinimini karşıladığı, mermer ve plaka taş olarak üretilmesinin bu taştan elde edilen geliri 4 kat arttıracağı ve Şanlıurfa'nın Türkiye mermer üretiminde sahip olduğu \%7'lik payı \%11'e çıkartacağı sonucuna varılmıştır.

Anahtar Kelimeler — Ekonomik analiz, Fiziko-termal, Mermer, Mekanik, Şanlıurfa taşı.

\section{Some Engineering Properties and Economic Analysis of Sanliurfa Stone}

\author{
${ }^{1}$ Celal AĞAN, ${ }^{2}$ Mustafa ŞíT \\ ${ }^{1}$ Harran University, Civil Engineering Department, Sanliurfa, Turkey, celalagan@ harran.edu.tr \\ ${ }^{2}$ Harran University, Tourism Management Department, Sanliurfa, Turkey, msit@ harran.edu.tr
}

\begin{abstract}
Due to well appearence, easy cutting, heat insulation and its strength, Sanliurfa stone has been a major shelter material for all of the cultures lived in Sanliurfa since ancient times. However, after the invention of concrete Sanliurfa stone lost its importance, and begin to mostly use for aggregate and crushed stone industry. In this study, superior engineering properties and polishing performance of stone Sanliurfa stone were examined, and income losses caused by using for aggregate industry was questioned, and economic analysis was conducted. In the study, economic analysis was added differently from studies in the literature. As a result; the engineering properties of Sanliurfa stone satisfy the international standard's requirements, using as high valuable marble may 4-fold increase of the income, and Sanliurfa may increase its share in the Turkish marble production from $7 \%$ to $11 \%$.
\end{abstract}

Keywords - Economic analysis, Marble, Mechanical, Physico-thermal, Sanliurfa stone. 


\section{GİRIŞ}

Sanlıurfa İli şimdiye kadar tespit edilmiş dünya üzerindeki en eski yaşam merkezlerinden biri olup, yerleşim amaçlı kullanımı M.Ö. 10.000 tarihinden bu yana devam etmektedir. Burada yaşayan tüm medeniyetler Şanlıurfa taşının (ŞT) barınma amaçlı olarak uygun özelliklere sahip olduğunu zamanla ve tecrübe ederek belirlemiştir. ŞT gevrek ve masif yapısı sayesinde çok iyi plakalar elde etmek mümkün olmuştur. Üstelik ocaktan ilk çıkarıldığında ve nemini kaybetmediğinde çok rahat işlenebilmektedir. Havayla temas süresi arttıkça ŞT sertleşmekte, taş işleme ve çatlaksız plaka almak zorlaşmaktadır. ŞT içerisinde çok az da olsa saçınık olarak bulunan çört parçaları antik çağlarda taş keski aracı olarak kullanılmıştır. Böylece, ŞT içerisindeki çört parçaları kayadan sökülerek yine ŞT nin kesilmesi ve şekillendirilmesi amacıyla kullanılmıştır. Bu durum bilim camiasında "büyük avantaj, kesilen ve kesen bir arada" şeklinde yorumlanmaktadır. Kullanım kolaylığının ve bol miktarda bulunmasının yanı sıra, ŞT'nın yüksek 1s1 yalıtımı sağladığı da zamanla anlaşılmıştır. Böylece, antik çağlardan betonun icadına kadar olan sürede ŞT bu yörede en önemli barınak ve yapı malzemesi olarak kullanılmıştır. Bu yapılardan bazıları UNESCO Dünya Mirası Listesi'nde yer almıştır.

Beton ve betonarme yapıların imalatından sonra ŞT ve buna benzer diğer yapı doğal taşlarının eski önemini yitirdikleri görülmektedir. Bu süreçte ŞT çoğunlukla çimento sanayiinde agrega ve mıcır üretiminde kullanılmış, yapı taşı olarak nadiren eski yapıların tadilatlarında ve azınlıktaki birkaç estetik yapı meraklısı kişi tarafindan kullanılmıştır. ŞT ve diğer yapı taşlarının zamanla kullanımının azalmasındaki en büyük etken atmosferik ve diş etkenlere bağlı olarak taşlarda ve dolayısıyla yapılardaki deformasyon olmuştur [1-5]. [6-9] ŞT'nın doygunken basınç dayanımının 25-60 \%'ını kaybettiğini belirtmiştir. Yapı taşlarındaki dayanım kayıplarının büyük ve maliyetli hasarlara yol açtığı [10-16] tarafindan bildirilmiştir. Ancak, bu etken bu değerli ve eşsiz taşın kullanımının alternatifsiz terkine gerekçe olmamalıdır. Zira, [17] ŞT'nın iyileştirmesi üzerine deneyler yapmış ve ST'nın bazı koruma işlemlerine tabi tutulduktan sonra kullanılmasıyla taşın dayanımını koruduğunu belirlemiştir. Ayrıca, ŞT'nın iyi derecede cila tutabildiğini ve böylece uzun y1llar doğal görüntüsünü muhafaza ettiğini ortaya koymuştur. Dolayisıyla, zikredilen olumsuzluklar nedeniyle bu ve buna benzer değerli doğal yapı taşlarının kullanımının terki yerine, iyileştirme ve bu olumsuzlukları ortadan kaldırma yöntemleri öncelikle araştırılmalıdır. Artan nüfus ve büyüyen şehirlerle birlikte mıcır ocakları neredeyse tamamen şehir içlerinde kalmıştır. Bu ocaklarda yapılan patlatmalı üretim çevrede ve asfalt yollarda büyük tahribatlara yol açmakta, hava kirliliğine neden olmakta, yeni imar çalışmalarının olumsuz etkilenmesine neden olmakta ve insanların hayatını tehlikeye atmaktadır (Şekil 1a).
ŞT'nın yapı taşı yerine taş tozu ve mıcır olarak kullanılması ülke ve şehir ekonomisinde de büyük kayıplara neden olmaktadır. Oysa, [17] ST'nın katma değeri yüksek mermer olarak kullanılabilirliğine dair ciddi bulgular elde etmiştir. Sekil 1a'da mıcır ocağı olarak kullanılan bazı sahalar ve Sekil $1 \mathrm{~b}$ 'de kesme taş ocağı olarak kullanılan bazı sahalar görülmektedir. Çok küçük bir alan kesme taş olarak değerlendirilirken, çok büyük sahalar mıcır ocağı olarak işletilmektedir. Her iki bölgenin ölçekli büyüklüğü karşılaştırıldığında ŞT'nın maruz kaldığı israf ve gelir kaybı daha iyi anlaşılmaktadır.

$\mathrm{Bu}$ çalışmada, öncelikle ŞT'nın daha önce literatürde yer almış mühendislik özellikleri sunulmuştur. Buna ek olarak, [17]'nin ŞT üzerine yaptığı iyileştirme ve koruma yöntemlerinin geçen 2 sene süresince dış etkenlere maruz bir ortamda etkinliğini ne derece koruduğu irdelenmiştir. Son olarak, ŞT'nın katma değeri yüksek mermer ve/veya kesme taş olarak kullanılması yerine mıcır olarak kullanılmasının neden olduğu gelir kayıpları sorgulanarak ekonomik analiz yapılmıştır. ŞT'nı daha önce bu kapsamda inceleyen herhangi bir çalışmaya literatür taramalarında rastlanılmaması, bu çalışmanın sonuçlarını daha da önemli kılmaktadır. Elde edilen sonuçların mevcut literatür eksikliğinin giderilmesine katkıda bulunması ve şehir ekonomisine artı yararlar sağlaması umut edilmektedir.

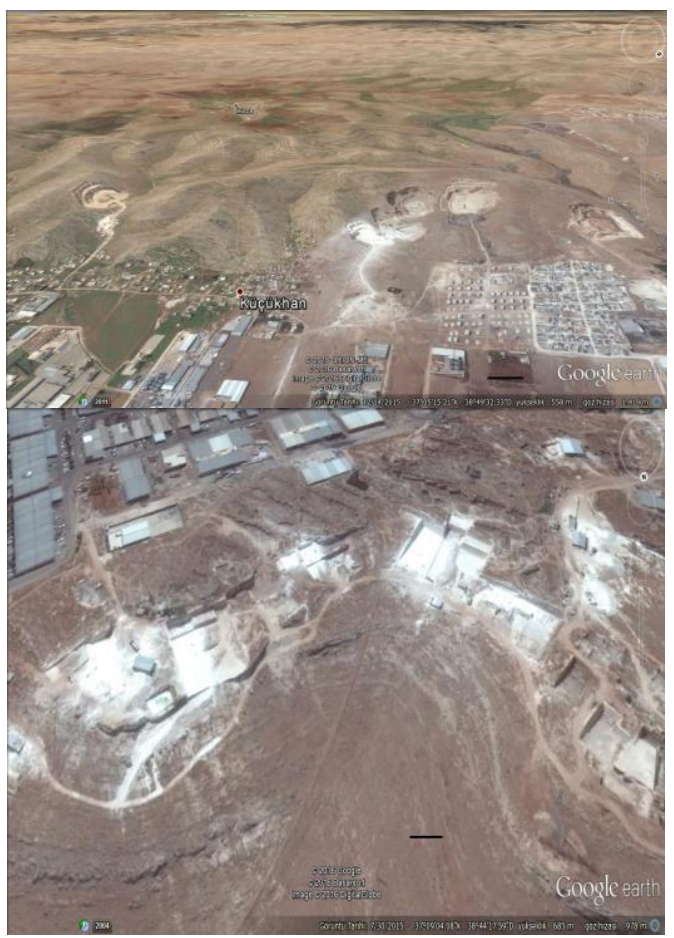

Şekil 1. Şanlıurfa'daki bazı (a) mıcır ve (b) kesme plaka taş ocakları (Some (a) gravel and (b) cutting plate quarries in Sanliurfa) 


\section{2. ŞANLIURFA YÖRESI VE KIREÇTAŞININ TANITIMI}

ŞT Güneydoğu Anadolu Bölgesinde Şanlıurfa İlinde yaklaşık $18.500 \mathrm{~km}^{2}$ 'lik bir alanı kaplamaktadır (Şekil 2). Bunlar genelde Miyosen-Eosen yaşlı olup, Şanlıurfa formasyonu adını almakta [18] ve yer yer yüzlerce metre kalınlığa ulaşmaktadır [6-9, 17]. Şanlıurfa'nın $120 \quad \mathrm{~km}$ kuzeydoğusundaki Karacadağ volkaniğinin püskürüğü olan Pliyo Kuvaterner bazalt bloklarına bölgede yer yer rastlanılmaktadır [19]. Bölgedeki horst-graben oluşumları ise Kuvaterner kil ile dolmuş ve bu dolgu alanlar dünyanın en verimli tarım arazilerini oluşturmuştur (Harran, Ceylanpınar, Bozova, Hilvan, Siverek ve Suruç ovaları gibi). [9] yaptığı ince kesit analizlerine göre bütün örnekler mikritikmikrosparitik-sparitiktir. Hakim minerali kalsit olup, yer yer fosillere, tebeşire ve çörte rastlanılmıştır. XRD analizlerine göre yer yer dolomite de rastlanılmıştır. Şanlıurfa'da antik (Şekil 3a) ve yeni (Şekil 3b) olmak üzere bazı taş ocakları bulunmaktadır. En eski yer üstü ocağının ne zaman işletildiği belirlenememiştir. Ancak, Göbeklitepe tapınağının ve taş işlemelerinin M.Ö. 10.000 yıllarında yapıldığı göz önüne alındığında az çok fikir sahibi olunmaktadır (Şekil 4). Bilinen en eski yeraltı taş ocağı ise Bazda taşocaklarıdır [9].

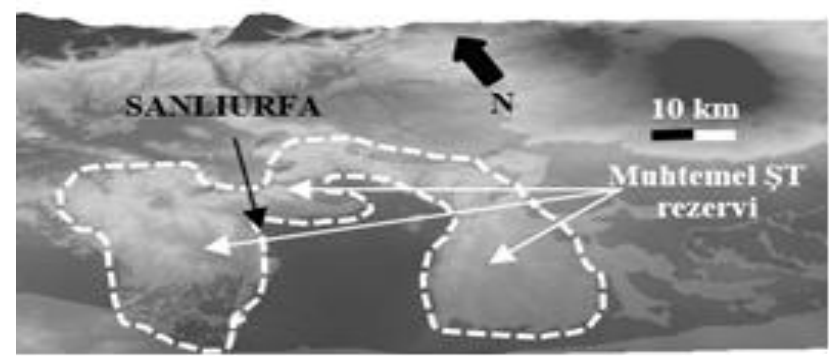

Şekil 2. Şanlıurfa kireçtaşı yüzlekleri

$\mathrm{Bu}$ ocaklarında kesin açılma tarihleri bilinmemekle birlikte 3.000 yıl önce yapılmış Harran kalesinin inşasında kullanılan taşların buradan çıkarıldığı göz önüne alındığında bu devasa 4 katlı Bazda'nın da yaşı ortaya çıkmaktadır (Şekil 5). Şanlıurfa merkezinde ŞT içerisinde açılmış irili-ufaklı, doğal-yapay olmak üzere 430 mağara bulunmaktadır. $\mathrm{Bu}$ mağaraların neredeyse tamamı yazlık ev, besin deposu, kar deposu ve ahır amaçlı kullanılmaktadır.

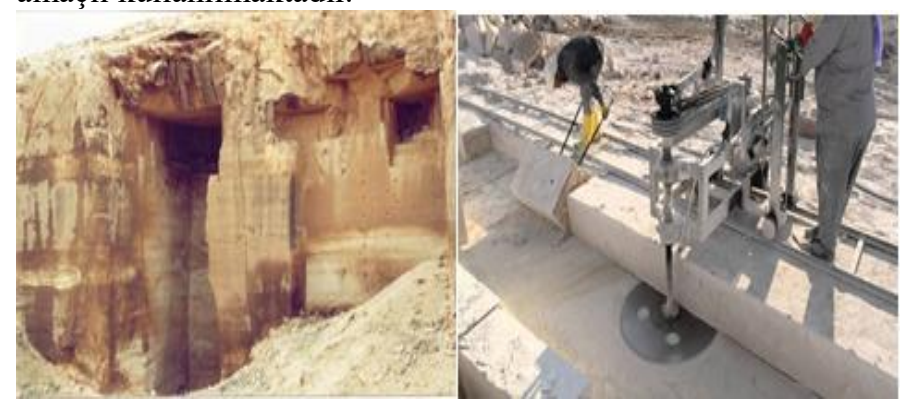

Şekil 3. Şanlıurfa'daki bazı (a) antik ve (b) yeni taş ocakları

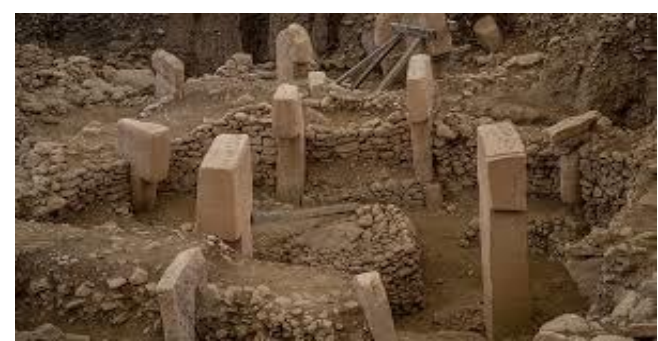

Şekil 4. Şanlıurfa-Göbeklitepe M.Ö. 10.000

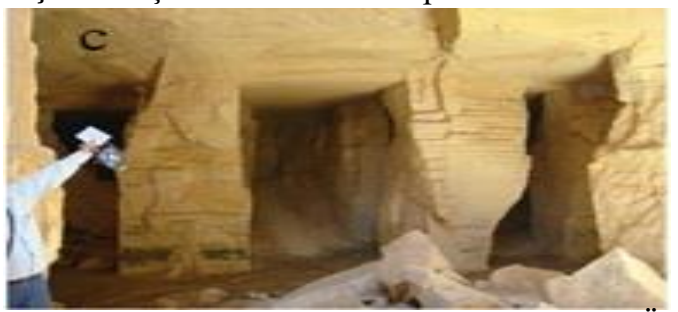

Şekil 5. Şanlıurfa-Bazda, 4 katlı yeraltı taş ocağı M.Ö. 1.000

\section{SSANLIURFA \\ TAŞININ \\ MÜHENDISLIK}

\section{ÖZELLIKLERI}

$\mathrm{Bu}$ bölümde ŞT'nın mühendislik özelliklerini ortaya çıkarmak amacıyla yapılan bazı çalışma sonuçları sunulmaktadır. Burada amaç, ŞT'nın yapı taşı olarak standartlara uygun olup olmadığını irdelemektir.

\subsection{Kaya kütlesi özellikleri}

Tablo 1. ŞT'nın RMR kaya kütlesi sınıflandırması

\begin{tabular}{|l|c|c|}
\hline & {$[20]$} & {$[9]$} \\
\hline Masif & $\begin{array}{c}80-90 \\
\text { (Çok iyi) }\end{array}$ & $\begin{array}{c}77-82 \\
\text { (İyi-Çok iyi) }\end{array}$ \\
\hline Kalın tabakalı & $60-80$ (İyi) & $64-74$ (İyi) \\
\hline İnce tabakalı & - & $\begin{array}{c}59-69 \\
\text { (Orta-İyi) }\end{array}$ \\
\hline
\end{tabular}

Bu bölümde [9] ve [20]'den alınan ve [21] tarafından önerilen Kaya kütlesi sınıflaması (RMR) sistemi referans alınarak yapılan ŞT'nın kaya kütlesi özellikleri Tablo 1'de sunulmuştur. Tablo 1'den de görüldüğü gibi, RMR kaya kütlesi sınıflama sistemine göre ŞT genelde "iyi-çok iyi” kaya grubuna girmektedir. Bu durum antik çağlardan bu yana ŞT'nın yapı taşı olarak kullanılmasının ne kadar yerinde bir tercih olduğunu göstermektedir. Kaya kütlesi sınıfının çok iyi-iyi olması ŞT'nın iyi bloklar ve plakalar halinde kesilebilirliğinin de bir göstergesidir.

\subsection{Kimyasal Bileşimi}

$\mathrm{Bu}$ bölümde [6] tarafindan atomik emilim spektrometresi kullanılarak yapılmış olan kimyasal analiz sonuçları sunulmuştur. Tablo 2'den de görüldüğü gibi ŞT'nın en büyük bileşeni $\mathrm{CaCO}^{3}$ olarak tespit edilmiştir. [9] yaptığı ince kesit analizlerine göre bütün örnekler mikritik-mikrosparitik- 
sparitiktir. XRD analizlerine göre yer yer fosillere, dolomite ve çörte rastlanılmıştır.

Tablo 2. ŞT'nın kimyasal bilişimi [6]

\begin{tabular}{|l|l|}
\hline \multicolumn{1}{|c|}{ Kimyasal bilişen } & \multicolumn{1}{c|}{ \% } \\
\hline $\mathrm{CaO}$ & $54.69 \pm 0.10$ \\
\hline Isınma kayıpları & $43.33 \pm 0.46$ \\
\hline Tanımlanamayan & $0.54 \pm 0.23$ \\
\hline $\mathrm{SiO}_{2}$ & $0.50 \pm 0.10$ \\
\hline $\mathrm{MgO}$ & $0.44 \pm 0.06$ \\
\hline $\mathrm{Al}_{2} \mathrm{O}_{3}$ & $0.29 \pm 0.02$ \\
\hline $\mathrm{Fe}_{2} \mathrm{O}_{3}$ & $0.20 \pm 0.04$ \\
\hline Toplam & 99.46 \\
\hline
\end{tabular}

\subsection{Fiziko-Termal Özellikleri}

Tablo 3. ŞT’nın fiziko-termal özellikleri

\begin{tabular}{|c|c|c|c|c|}
\hline Malz. özellikleri & [6] & {$[8]$} & [9] & [17] \\
\hline $\begin{array}{lr}\begin{array}{l}\text { Birim } \\
\text { ağırlık }\end{array} & \text { hacim } \\
& \left(\mathrm{kN} \cdot \mathrm{m}^{-3}\right)\end{array}$ & $\begin{array}{c}20.8 \pm \\
0.80\end{array}$ & 20.60 & $17.5 \pm 0.80$ & - \\
\hline $\begin{array}{lr}\text { Doygun } & \text { birim } \\
\text { hacim } & \text { ağırlık } \\
\left(\mathrm{kN} \cdot \mathrm{m}^{-3}\right) & \end{array}$ & $\begin{array}{c}22.5 \pm \\
0.40\end{array}$ & & $20.2 \pm 0.70$ & - \\
\hline Özgül ağırlık & - & - & $2.64 \pm 0.04$ & - \\
\hline Yoğunluk $\left(\mathrm{gr} / \mathrm{cm}^{3}\right)$ & $\begin{array}{c}2.57 \pm \\
0.00\end{array}$ & - & 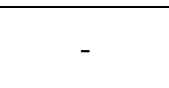 & - \\
\hline Boşluk oranı (\%) & $\begin{array}{c}19.2 \pm \\
3.10\end{array}$ & - & - & - \\
\hline $\begin{array}{l}\text { Ağırlıkça su emme } \\
(\%)\end{array}$ & $\begin{array}{l}8.4 \pm \\
2.50\end{array}$ & - & $15.0 \pm 1.10$ & - \\
\hline Gözeneklilik (\%) & $\begin{array}{c}17.2 \pm \\
4.30\end{array}$ & - & $25.4 \pm 3.90$ & - \\
\hline $\begin{array}{l}\text { Donma-çöz. son. } \\
\text { kütle kayb1 }(\%)\end{array}$ & $\begin{array}{c}0.07 \pm \\
0.01\end{array}$ & - & - & - \\
\hline 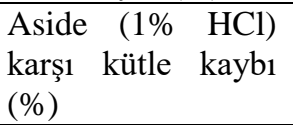 & - & - & - & 13 \\
\hline $\begin{array}{l}\text { Isıl iletkenlik } \\
\left(\mathrm{W} \cdot \mathrm{m}^{-1} \cdot \mathrm{K}^{-1}\right)\end{array}$ & $\begin{array}{c}1.42 \pm \\
0.09\end{array}$ & 0.91 & - & - \\
\hline $\begin{array}{l}\text { Özgül 1s1 } \\
\left.{ }^{1} . \mathrm{C}^{-1}\right)\end{array}$ & $\begin{array}{l}1,041 \\
\pm 0.9\end{array}$ & - & - & - \\
\hline $\begin{array}{l}\text { Isıl yayınım }\left(\mathrm{m}^{2} \cdot \mathrm{s}^{-}\right. \\
\left.{ }^{1} \cdot 10^{-7}\right)\end{array}$ & $\begin{array}{c}6.64 \pm \\
0.98 \\
\end{array}$ & - & - & - \\
\hline $\begin{array}{l}\text { Kuru P-dalga hızı } \\
\left(\mathrm{km} \cdot \mathrm{s}^{-1}\right)\end{array}$ & $\begin{array}{c}3.27 \pm \\
0.24 \\
\end{array}$ & - & $2.72 \pm 1.10$ & - \\
\hline $\begin{array}{l}\text { Doygun P-dalga } \\
\text { h1z1 }\left(\mathrm{km} \cdot \mathrm{s}^{-1}\right)\end{array}$ & - & - & $2.53 \pm 5.10$ & - \\
\hline $\begin{array}{l}\text { Kuru S-dalga hızı } \\
\left(\mathrm{km} \cdot \mathrm{s}^{-1}\right)\end{array}$ & - & - & $1.42 \pm 1.70$ & - \\
\hline $\begin{array}{l}\text { Doygun S-dalga } \\
\text { h1z1 }\left(\mathrm{km} \cdot \mathrm{s}^{-1}\right)\end{array}$ & - & - & $1.17 \pm 5.00$ & - \\
\hline
\end{tabular}

$\mathrm{Bu}$ bölümde [6, 8, 9] tarafindan ŞT'nın fiziko-termal özelliklerinin tespitine yönelik daha önce yapılmış olan test sonuçları Tablo 3'de sunulmuştur. Tablo 3'de görüldüğü gibi, ŞT'nın birim hacim ağırlığı [22]'de verilen üst limitin (25
kN.m ${ }^{-3}$ ) altında kalmaktadır. Boşluk oranı standartta verilen limitten 8 kat, gözeneklilik ise 10 kat daha fazladır. Ağırlıkça su emme oranı [23] standardı göz önüne alındığında (en fazla $12 \%$ ) [6]'ya göre sınırlar içinde, ancak [9]'a göre sınırın biraz üstündedir. Yoğunluğu [23] standardı sınırları dahilindedir (en az 1.7 gr.cm ${ }^{-3}$ ). Donma-çözülme sonrası kütle kaybı ise [24] standardı sınırları dahilindedir (en fazla $0.1 \%$ ). Böylece, ŞT'nın gözeneklilik ve boşluk oranı verileri hariç tüm fiziksel parametreleri standartlar dahilindedir. Gözeneklilik ve boşluk oranı verilerinin olması gerekenden fazla olmasının bir eksiklik olarak algılanmaması gerektiği düşünülmektedir. Çünkü, bu parametreler ŞT'na esas değer katan ve iyi bir yalıtım malzemesi olmasında baş rolü oynamaktadır. Zaten 1sı yalıtım parametreleri de literatürde verilen $[25,26]$ pek çok doğal yapı taşına göre daha yüksek çıkmıştır.

\subsection{Mekanik Özellikleri}

Tablo 4. ŞT'nın mekanik özellikleri

\begin{tabular}{|c|c|c|c|c|}
\hline Malzeme özellikleri & [6] & [8] & [9] & [17] \\
\hline $\begin{array}{l}\text { Kuru tek eksenli basınç } \\
\text { dayanımı }(\mathrm{MPa})\end{array}$ & 17.8 & 15 & 15.62 & - \\
\hline $\begin{array}{l}\text { Doygun tek eksenli basınç } \\
\text { dayanımı }(\mathrm{MPa})\end{array}$ & 14.7 & - & 14.10 & - \\
\hline $\begin{array}{l}\text { Kuru Brezilya çekme } \\
\text { basıç dayanımı }(\mathrm{MPa})\end{array}$ & - & - & 1.83 & - \\
\hline $\begin{array}{l}\text { Doygun Brezilya çekme } \\
\text { basınç } \quad \text { dayanımı }(\mathrm{MPa})\end{array}$ & - & - & 0.81 & - \\
\hline $\begin{array}{l}\text { Kuru eğilme basıncı } \\
\text { dayanımı }(\mathrm{MPa})\end{array}$ & - & - & 3.77 & - \\
\hline $\begin{array}{l}\text { Doygun eğilme basıncı } \\
\text { dayanımı (MPa) }\end{array}$ & - & - & 1.47 & - \\
\hline $\begin{array}{l}\text { Donma-çözülme sonrası } \\
\text { k.tek eks.bas.day.(MPa) }\end{array}$ & 16.3 & - & - & - \\
\hline $\begin{array}{l}\text { Donma-çözülme sonrası } \\
\text { d.tek eks.bas.day.(MPa) }\end{array}$ & 12.7 & - & - & - \\
\hline $\begin{array}{l}\text { Yanma sonrası tek eksenli } \\
\text { basınç dayan. }(\mathrm{MPa})\end{array}$ & - & - & - & 11.2 \\
\hline $\begin{array}{l}\text { Kuru Schmidt çekici } \\
\text { dayanımı }(\mathrm{MPa})\end{array}$ & 21 & - & - & - \\
\hline $\begin{array}{l}\text { Doygun Schmidt çekici } \\
\text { dayanımı }(\mathrm{MPa})\end{array}$ & 16 & - & 12.6 & - \\
\hline Elastik modül $(\mathrm{GPa})$ & 13.9 & 18 & 13.1 & - \\
\hline Poisson oran1 & 0.31 & 0.24 & 0.22 & - \\
\hline $\begin{array}{l}\text { Suda dağılmaya dayanım } \\
\text { indeksi } \operatorname{Id}_{2}(\%)\end{array}$ & - & - & 87.5 & - \\
\hline
\end{tabular}

$\mathrm{Bu}$ bölümde [6, 8, 9] tarafından ŞT'nın mekanik özelliklerinin tespitine yönelik daha önce yapılmış olan test sonuçları Tablo 4'de sunulmuştur. Tablo 4'den de görüldüğü gibi, ŞT'nın tek eksenli basınç dayanımı [23] standardında verilen en az 2.8 MPa koşulunu kuru halde sağlamakta, ancak doygun halde sağlayamamaktadır. Eğilme basıncı dayanımı 
en az $12 \mathrm{MPa}$ koşulunu hem kuru halde hem de doygun halde sağlamaktadır.

\section{5 ŞT'nı iyileştirme yöntemlerinin performansı}

Bu bölümde [17] tarafından ŞT'nın dayanım parametrelerinin korunmasına yönelik daha önce yapılmış olan iyileştirme çalışmaları sonuçları Şekil 6'da sunulmuştur. Şekil 6'dan da görüldüğü gibi, iyileştirme çalışmaları oldukça verimli olmuş ve asit ve su kaynaklı ağırlık kayıpları doğal ŞT'ında 13\% iken, çeşitli koruyucularla iyileştirilen ŞT'ında ağırlık kayıpları 1\%’e kadar indirgenmiştir.

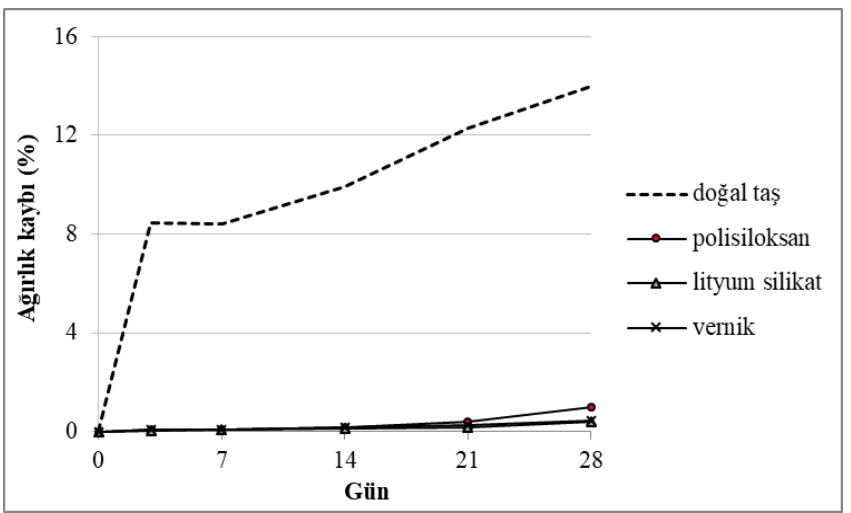

Şekil 6. Doğal ve iyileştirilmiş ŞT’nın asite karşı dayanım

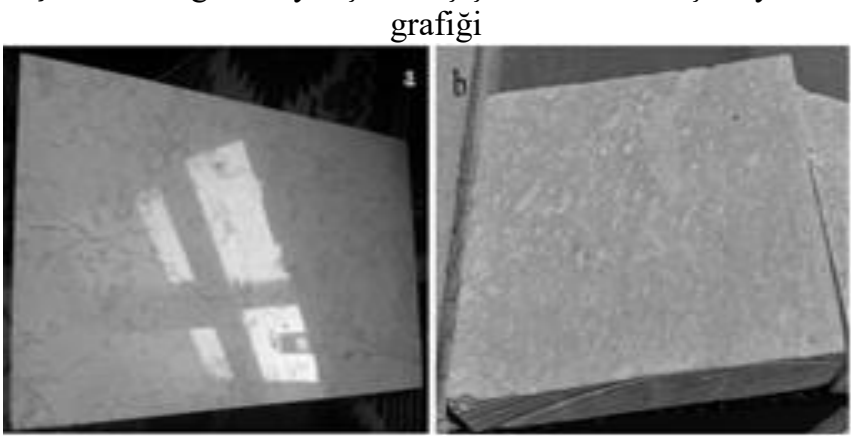

Şekil 7. ŞT'nın (a) cilalanmış [17], ve (b) cilalandıktan 2 yıl sonraki görünümü

[17] tarafindan ŞT'nın görsellik anlamında korunmasına yönelik daha önce yapılmış olan cilalama çalışmaları sonucu Şekil 7a'da sunulmuştur. Şekil 7a'dan da görüldüğü gibi, cilalama çalışmaları oldukça etkin sonuç vermiştir. Şekil 7b'de ise bu cilalama işlemine tutulan plakaların 2 y1 boyunca atmosferik etkilere direk maruz bırakıldıktan sonraki görünümü sunulmaktadır. Şekil 7b'den görüldüğü gibi atmosferik koşullarda aradan geçen 2 yıla rağmen sıcak güneşten ve toprak yağmurlarından kaynaklı hafif sararmayla birlikte cilalama işlemi ŞT'nı etkin olarak koruyabilmiştir.

\section{EKONOMIK ANALIZ}

Önceki bölümlerde ŞT'nın kaplama taşı ve mermer olarak kullanıma uygunluğu teknik anlamda ortaya konulmuştur. $\mathrm{Bu}$ bölümde ise, ŞT'nın mıcır olarak kullanılmasıyla ortaya çıkan milli gelir kayıpları analiz edilmiştir. Şekil 1a ve 1b incelenip ölçekleri karşılaştırıldığında çok daha büyük ölçekte katma değeri düşük micır üretimi nedeniyle heba edilen devasa ŞT rezervleri görünmektedir.

Şanlıurfa'da işlenmemiş taş ve işlenmiş taş arasındaki ekonomik fayda farkını ortaya koyabilmek için [27]'den alınan verilerle piyasadan elde edilen birim fiyatlar üzerinden Şanlıurfa'daki doğal taş ve mermer sektörü ekonomik fayda yönünden analiz edilmiştir. Tablo 5'de 2015 yılı itibariyle Şanlıurfa ilindeki doğal taş ve mermer sektörüne ait üretim ve ekonomik fayda verileri bulunmaktadır. Buna göre mermer ve plaka taş üreten toplam 8 firma bulunurken, mıcır ve hazır beton üreten 44 firma bulunmaktadır. Bu sektörde en fazla işletme micır ve taş tozu üretiminde görülmektedir. Tabloda firmaların toplam üretim kapasiteleri ve piyasadan araştırılan güncel fiyatlar üzerinden hesaplanan Şanlıurfa'da ki doğal taş ve mermer sektörü ekonomik fayda verileri de bulunmaktadır. Fiyat araştırmasında veriler toplam üretim üzerinden alındığından malzemenin cinsine göre değişen fiyatlar üzerinden ortalama bir birim fiyatı tespit edilmiştir.

Tablo 5. Şanlıurfa doğal taş ve mermer sektörü 2017 yılı üretimi ve ekonomik fayda verileri [27]

\begin{tabular}{|c|c|c|c|c|}
\hline & $\begin{array}{c}\text { Firma } \\
\text { adedi }\end{array}$ & Üretim & $\begin{array}{c}\text { Birim } \\
\text { fiyatı }\end{array}$ & $\begin{array}{c}\text { Ekonomik } \\
\text { fayda }\end{array}$ \\
\hline $\begin{array}{c}\text { Plaka } \\
\text { Mermer }\end{array}$ & 7 & $\begin{array}{c}176.641 \\
\mathrm{~m}^{2} / \mathrm{y} 1 \mathrm{l}\end{array}$ & $\begin{array}{c}48 \\
\mathrm{TL} / \mathrm{m}^{2}\end{array}$ & $8.478 .768 \mathrm{TL}$ \\
\hline $\begin{array}{c}\text { İşlenmiş } \\
\text { Mermer }\end{array}$ & 1 & $\begin{array}{c}121.345 \\
\mathrm{~m}^{2} / \mathrm{y} 1 \mathrm{l}\end{array}$ & $\begin{array}{c}119 \\
\mathrm{TL} / \mathrm{m}^{2}\end{array}$ & $\begin{array}{c}14.440 .055 \\
\mathrm{TL}\end{array}$ \\
\hline Urfa Taş1 & 4 & $\begin{array}{c}109.356 \\
\mathrm{~m}^{2} / \mathrm{y} 1 \mathrm{l}\end{array}$ & $\begin{array}{c}46 \\
\mathrm{TL} / \mathrm{m}^{2}\end{array}$ & $5.030 .376 \mathrm{TL}$ \\
\hline Micır & 15 & $\begin{array}{c}5.418 \\
\text { ton/y1l }\end{array}$ & $\begin{array}{c}29 \\
\mathrm{TL} / \mathrm{ton}\end{array}$ & $157.122 \mathrm{TL}$ \\
\hline Taş tozu & 15 & $\begin{array}{c}2.932 \\
\text { ton/y1l }\end{array}$ & $\begin{array}{c}35 \\
\mathrm{TL} / \mathrm{ton}\end{array}$ & $102.620 \mathrm{TL}$ \\
\hline
\end{tabular}

$\mathrm{Bu}$ verilere göre; plaka mermer üretiminden elde edilen ekonomik gelir 8.478.768 TL iken, işlenmiş mermer üretiminden elde edilen gelir 14.440.055 TL olmuştur. Yine işlenmemiş taşlar içerisinde urfa taşı üretiminden yılda 5.030.376 TL ekonomik fayda sağlanmıştır. Sektör içerisinde en az gelir micır ve taş tozundan elde edilmiş ve sırasıyla 157.122 TL ve 102.620 TL olarak gerçekleşmiştir.

Sonuç olarak bakıldığında, Şanlıurfa ilinde üretilen doğal taşların işlendiğinde ekonomik faydasının daha da arttığı görülmektedir. Örneğin, $\mathrm{m}^{2}$ bazında işlenmiş mermer üretiminin işlenmemiş mermer üretimine göre daha az olmasına rağmen ekonomiye sağladığı fayda daha yüksek gerçekleşmiştir. [28]'in belirttiği gibi Şanlıurfa ilinde de mermerlerin ocaklardan işlenmeden micır ve/veya blok halinde satışı azaltılmalı, işlenerek ve katma değeri yükseltilerek dış pazarlara satılması sağlanmalıdır. Şekil 8'de 
görüldüğü gibi, ŞT'nın işlenmeden ve işlenerek satılması arasında büyük fiyat farkları ve milli gelir kayıpları oluşmaktadır. [29]'un verilerine göre Türkiye'de toplam mermer üretimi son 5 yilda $4.200 .000 \mathrm{~m}^{2}$ civarında gerçekleşmiştir.

Buna göre, Şanlıurfa ilinde plaka mermer ve işlenmiş mermer üretim miktarı Türkiye'de ki toplam mermer üretimin \%7'si civarındadır. Diğer yandan, plaka taş, mıcır ve taş tozu olarak işlenen ŞT'nın mermer olarak üretilmesi halinde ŞT'nın Türkiye'deki toplam mermer üretimindeki payını \%11'ine yükseltmek mümkün olacaktır. Ancak bölgede katma değeri yüksek olması bakımından mermer üretimi ihtiyaç olduğu kadar katma değeri düşük olsa da mıcır ve taş tozu üretimi de ihtiyaçtır. $\mathrm{Bu}$ ihtiyacın yerel kaynaklardan karşılanmaması durumunda bölgeye ekstra mali külfet getirme olasılığı göz ardı edilmemelidir.

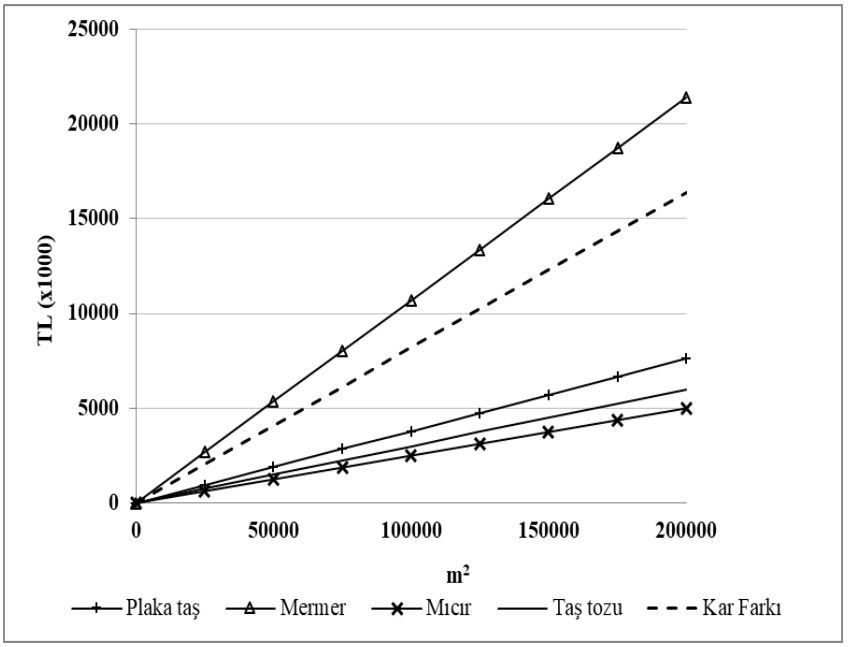

Şekil 8. ŞT'nın işlenmeden ve işlendikten sonra sağladığ ekonomik fayda grafiği

\section{SONUÇ VE ÖNERILER}

Bu çalışmada ŞT'nın kaya kütlesi sınıflandırması, kimyasal bileșenleri, termal özellikleri, fiziksel özellikleri, mekanik özellikleri ve korunabilmesi ile ilgili veriler irdelenmiştir. Ayrıca, ŞT'nın mermer ve/veya yapı taşı olarak kullanılmaktansa, taş tozu ve mıcır olarak kullanılmasının ülke ve şehir ekonomisinde neden olduğu büyük kayıplar analiz edilmiştir.

Gerek binlerce yıllık deneyimler, gerekse de literatür çalışmaları ŞT'nın iyi bir yapı taşı olduğunu kanıtlamıştır. ŞT'nın sahip olduğu fiziksel ve mekanik parametreler uluslararası standartların gereksinimlerini karşılayacak düzeydedir. Diğer yandan, [17] ŞT'nın iyi cila tutabildiğine ve katma değeri yüksek mermer olarak kullanılabilirliğine dair ciddi bulgular elde etmiştir.

Çok büyük rezerve sahip ŞT'nın, Şekil 2a'dan görüldüğü gibi çok küçük bir alanı kesme taş olarak değerlendirilirken, çok daha büyük sahaları mıcır ocağı olarak işletilmektedir. Her iki bölgenin ölçekli büyüklüğü karşılaştırıldığında ŞT'nın maruz kaldığı israf ve milli gelir kaybı daha iyi anlaşılmaktadır. Bu kapsamda yapılan ekonomik analiz sonuçlarına göre, Şekil 8'den de görüldüğü gibi ŞT'nın mıcır olarak kullanılması yerine katma değeri yüksek mermer olarak kullanılması halinde elde edilen geliri 4-5 kat arttırmak mümkün olmaktadır. Diğer yandan, ŞT'nın mermer ve/veya plaka taş halinde kullanılmasının micır ve taş tozu üretimini aksatmayacağı düşünülmektedir. Mermercilik ve plaka taş kesimi faaliyetleri esnasında çıkan büyük miktardaki toz ve atık taş da endüstrinin ihtiyacı olan hammaddeyi karşılayabilecektir [30-32]. Ancak, uzun yıllık veriler elde edilemediğinden ekonometrik analiz yapılamaması ve kesin bir kar artış oranının belirlenememesi bu çalışmanın en zayıf yönüdür. Ekonometrik analizin yapılabilmesi için en az 30 yıllık veriye ihtiyaç duyulmaktadır. Bundan sonra yapılacak çalışmalarda, zaman serisi analizleri, birim kök, eşbütünleşme, nedensellik testleri, hata düzeltme modelleriyle panel veri analizi yapılarak Urfa taşının ekonomik analizinin geliştirilmesi önerilir.

ŞT'nı daha önce bu kapsamda inceleyen herhangi bir çalışmaya literatür taramalarında rastlanılmaması, bu çalışmanın sonuçlarını daha da önemli kılmaktadır. Çalışmada literatürde ki çalışmalardan farklı olarak ekonomik analiz ekleniştir. Elde edilen sonuçların mevcut literatür eksikliğinin giderilmesine katkıda bulunması, şehir ve ülke ekonomisine artı yararlar sağlaması umut edilmektedir.

Teşekkürler: Yazarlar plaka temini, cilalama, üretim verileri ve birim fiyatların tedarikinde yardımlarından dolayı Selahattin Yanmaz (Yanmaz Karo Ltd.Şti) teşekkürlerini sunar.

\section{SEMBOLLER}

$\begin{array}{ll}\mathrm{Al}_{2} \mathrm{O}_{3} & : \text { Alüminyum oksit } \\ \mathrm{ASTM} & : \text { Amerikan test ve malzemeler derneği } \\ \mathrm{CaCO}_{3} & : \text { Kalsiyum karbonat } \\ \mathrm{CaO} & : \text { Kalsiyum oksit } \\ \mathrm{Fe}_{2} \mathrm{O}_{3} & : \text { Demir oksit } \\ \mathrm{GPa} & : \text { Gigapascal } \\ \mathrm{gr} . \mathrm{cm}^{-3} & : \text { Gram/santimetreküp } \\ \mathrm{HCl} & : \text { Hidroklorik asit } \\ \mathrm{J} & : \text { Joule } \\ \mathrm{kg} & : \text { Kilogram } \\ \mathrm{km} & : \text { Kilometre } \\ \mathrm{kN} . \mathrm{m}^{-3} & : \text { Kilonewton/metreküp } \\ \mathrm{m} & : \text { Metre } \\ \mathrm{MgO} & : \text { Magnezyum oksit } \\ \mathrm{M} . \mathrm{O} . & : \text { Milattan önce } \\ \mathrm{MPa} & : \text { Megapascal }\end{array}$




$\begin{array}{ll}\mathrm{RMR} & \text { : Kaya kütlesi sınıflaması } \\ \mathrm{s} & \text { : Saniye } \\ \mathrm{SiO}_{2} & \text { : Silisyum oksit } \\ \mathrm{ST} & \text { : Sanlıurfa taş1 }\end{array}$

SUTSO: Sanliurfa Ticaret ve Sanayi Odası

TL : Türk Liras1

TS : Türk Standartları

UNESCO: Birleşmiş Milletler Eğitim, Bilim ve Kültür Örgütü

$\begin{array}{ll}\text { XRD } & \text { : X-Işınları Kırınımı } \\ \mathrm{W} & \text { : Watt } \\ \% & \text { : Yüzde oran }\end{array}$

\section{KAYNAKÇA}

[1] Winkler E.M., Stone: Properties, durability in man's environment. Springer-Verlag, Berlin, 313, 1973.

[2] Azzoni A., Bailo F., Rondena E., Zanietti A., Assessment of texture coefficient for different rock types and correlation with uniaxial compressive strength and rock weathering, Rock Mechanics and Rock Engineering 29 (1), 39-46, 1996.

[3] Singh T.N., Singh S.K., Mishra A., Singh P.K., Singh V.K., Effect of acidic water on physico-mechanical behaviour of rock. Indian Journal of Engineering and Materials Sciences 6, 66-72, 1999.

[4] Sharma P.K., Khandelwal M., Singh T.N., Variation on physico-mechanical properties of Kota stone under different watery environments. Building and Environment 42, 4117-4123, 2007.

[5] Ozcelik Y., Ozguven A., Water absorption and drying features of different natural building stones. Construction and Building Materials 63, 257-270, 2014.

[6] Turgut P., Yesilnacar M.I., Bulut H., Physico-thermal and mechanical properties of Sanliurfa limestone, Turkey. Bulletin of Engineering Geology and The Environment 67, 485-490, 2008.

[7] Kulaksiz S., Agan C., Urfa (Harran) Bazda Ancient Underground Marble Quarying. The Proceeding book of the 3rd Balkan Mining Congress (BALKANMINE 2009), ISBN= 978-9944-89-782-2, Izmir, Turkey, 683-689, 2009.

[8] Agan C., Investigation into the usage of Sanliurfa limestones in Turkey as underground storage cavern with regard to some engineering properties. International Journal of the Physical Sciences 6 (33), 7629-7637, 2011.

[9] Agan C., Yesilnacar M.I., Genis M., Kulaksiz S., Ulusay R., Aydan O., Yucel M.D., A preliminary geoengineering assessment of Bazda antique underground quarries in Şanliurfa, Turkey. The Proceeding book of the ISRM International Symposium: Rock Mechanics for Resources, Energy, and Environment (EUROCK 2013), Wroclaw, Poland, September 2013, 93-98, 2013.

[10] Zezza U., Physical- mechanical properties of quarry and building stones. In: Veniale, F., Zezza, U. (Eds.), Analytical Methodologies of Damage Stones, Pavia. 1-20, 1990.
[11] Kaufmann O., Quinif Y., Cover-collapse sinkholes in the "Tournaisis" area, southern Belgium. Engineering Geology 52, 15-22, 1999.

[12] Bernd F., Kurt H., Kartierung und Bewertung von Verwitterungsschaden an Natursteinbauwerken (in German), Zeitschrift Deutschen Gesellschaft Geowissenschaften 21, 7 24, 2005.

[13] Devos A., Sosson C., Lejeune O., Fronteau G., Role des contextes geomorphologique et geologique dans l'abandon des carrieres de pierre du Lutetien autour de Reims (in French). International symposium "Pierres du patrimoine europeen: Economie de la pierre de l'Antiquite a la fin du XVIIIe siecle en Europe", 18-21 Octobre 2005, ChateauThierry, 64, 2005.

[14] Fronteau G., Moreau C., Thomachot-Schneider C., Barbin V., Variability of some Lutetian building stones from the Paris Basin, from characterisation to conservation. Engineering Geology 115, 158-166, 2010.

[15] Sariisik A., Sariisik G., Environmental interaction properties of marbles used in the restoration of historical monuments (Dalyan-Kaunos). Ekoloji 79, 12-19, 2011.

[16] Bednarik M., Moshammer B., Heinrich M., Holzer R., Laho M., Uhlir C., Unterwurzacher M., Rabeder J., Engineering geological properties of Leitha Limestone from historical quarries in Burgenland and Styria, Austria. Engineering Geology 176, 66-78, 2014.

[17] Agan C., A preliminary study on the conservation and polishing performance of Sanliurfa limestones as a traditional building material, Bull Eng Geol Environ 75 (1), 13-25, 2016.

[18] Canakci H., Demirboga R., Karakoc M.B., Sirin O., Thermal conductivity of limestone from Gaziantep (Turkey). Building and Environment 42, 1777-1782, 2007.

[19] Yesilnacar M.I., Cetin H., Site selection for hazardous wastes: A case study from the GAP area, Turkey, Engineering Geology, 81/4, 371-388, 2005.

[20] Kulaksiz S., Aydan O., Characteristics of ancient underground quarries of Turkey and Egypt and their comparison. 22nd World Mining Congress, Istanbul, 607614, 2010.

[21] Bieniawski Z.T., Engineering Rock Mass Classifications. John Wiley and Sons, New York, 237, 1989.

[22] TS 1910, Dogal yapi taslari, Turk Standartlari Enstitusu, Ankara, Turkey, 2005.

[23] ASTM C568 M-15, Standard Specification for Limestone Dimension Stone, ASTM International, USA, 2015.

[24] ASTM D5312 M-12, Standard Test Method for Evaluation of Durability of Rock for Erosion Control Under Freezing and Thawing Conditions, ASTM International, USA, 2013.

[25] Ozisik M.N., Heat transfer-A basic approach, McGraw Hill, ISE Editions, ISBN 13: 9780070479821, New York, USA, 1985.

[26] Kreider J.F., Curtiss P., Rabl A., Heating and cooling 
of buildings-design for efficiency. McGraw-Hill, ISBN: 9780078347764, New York, USA, 2002.

[27] ŞUTSO, 2017 y1lı Şanlıurfa şirketleri üretim miktarları, Şanlıurfa Ticaret ve Sanayi Odası, 2018.

[28] Eraslan H., İpçioğlu İ., Haşit G., Erşahan B., Bilecik Bölgesi Mermer Sektörünün Uluslar Arası Rekabetçilik Analizi: Sektörel Sorunlar ve Çözüm Önerileri, Mustafa Kemal Üniversitesi Sosyal Bilimler Enstitüsü Dergisi, Cilt:5, Say1:10, 193-217, 2008.

[29] Enerji ve Tabii Kaynaklar Bakanlığı, Doğal Taş Sektör Raporu, 2015. http://www.enerji.gov.tr/tr-
TR/Sayfalar/Dogal-Taslar

[30] Arslan M., Demir İ., Kırşehir yöresi kırmataş agregalarının mühendislik özellikleri, Gazi Üniv. Müh. Mim. Fak. Dergisi, Cilt:20, No:3, 335-346, 2005.

[31] Akbulut H., Gürer C., Atık mermerlerin asfalt kaplamalarda agrega olarak değerlendirilmesi, İMO Teknik Dergi, Sayı: 84, Cilt: 17, Yazı 261, 3943-3960, 2006.

[32] Demir İ., Uzun İ., Kırşehir-Kaman yöresi granitlerin kırmataş agrega olarak kullanılabilirlik özellikleri, Gazi Üniv. Müh. Mim. Fak. Dergisi, Cilt:22, No:3, 369-378, 2007. 